\title{
RESEARCH
}

Open Access

\section{Clinical, biochemical and genetic profiles of patients with mucopolysaccharidosis type IVA (Morquio A syndrome) in Malaysia: the first national natural history cohort study}

Huey Yin Leong ${ }^{1 *}$ D, Nor Azimah Abdul Azize ${ }^{2}$, Hui Bein Chew ${ }^{1}$, Wee Teik Keng ${ }^{1}$, Meow Keong Thong ${ }^{3}$, Mohd Khairul Nizam Mohd Khalid², Liang Choo Hung ${ }^{4}$, Norzila Mohamed Zainudin ${ }^{4}$, Azura Ramlee', Muzhirah Aisha Md Haniffa ${ }^{1}$, Yusnita Yakob ${ }^{2}$ and Lock Hock Ngu ${ }^{1}$

\begin{abstract}
Background: Mucopolysaccharidosis IVA (MPS IVA) is an autosomal recessive lysosomal storage disease due to $\mathrm{N}$-acetylgalactosamine-6-sulfatase (GALNS) deficiency. It results in accumulation of the glycosaminoglycans, keratan sulfate and chondroitin-6-sulfate, leading to skeletal and other systemic impairments. Data on MPS IVA in Asian populations are scarce.

Methods: This is a multicentre descriptive case series of 21 patients comprising all MPS IVA patients in Malaysia. Mutational analysis was performed by PCR and Sanger sequencing of the GALNS gene in 17 patients.

Results: The patients ( 15 females and 6 males) had a mean age ( \pm SD) of 15.5 ( \pm 8.1) years. Mean age at symptom onset was $2.6( \pm 2.1)$ years and at confirmed diagnosis was $6.9( \pm 4.5)$ years. The study cohort included patients from all the main ethnic groups in Malaysia - 57\% Malay, 29\% Chinese and 14\% Indian. Common presenting symptoms included pectus carinatum (57\%) and genu valgum (43\%). Eight patients (38\%) had undergone surgery, most commonly knee surgeries (29\%) and cervical spine decompression (24\%). Patients had limited endurance with lower mean walking distances with increasing age. GALNS gene analysis identified 18 distinct mutations comprising 13 missense, three nonsense, one small deletion and one splice site mutation. Of these, eight were novel mutations (Tyr133Ser, Glu158Valfs*12, Gly168*, Gly168Val, Trp184*, Leu271Pro, Glu320Lys, Leu508Pro). Mutations in exons 1, 5 and 9 accounted for $51 \%$ of the mutant alleles identified.
\end{abstract}

Conclusions: All the MPS IVA patients in this study had clinical impairments. A better understanding of the natural history and the clinical and genetic spectrum of MPS IVA in this population may assist early diagnosis, improve management and permit timely genetic counselling and prenatal diagnosis.

Keywords: Natural history, Diagnosis, Mucopolysaccharidosis IVA, GALNS, Malaysia

\footnotetext{
* Correspondence: hueyyinleong@yahoo.com

${ }^{1}$ Genetics Department, Hospital Kuala Lumpur, Ministry of Health Malaysia,

Jalan Pahang, 50586 Kuala Lumpur, Malaysia

Full list of author information is available at the end of the article
}

(c) The Author(s). 2019 Open Access This article is distributed under the terms of the Creative Commons Attribution 4.0 International License (http://creativecommons.org/licenses/by/4.0/), which permits unrestricted use, distribution, and reproduction in any medium, provided you give appropriate credit to the original author(s) and the source, provide a link to the Creative Commons license, and indicate if changes were made. The Creative Commons Public Domain Dedication waiver (http://creativecommons.org/publicdomain/zero/1.0/) applies to the data made available in this article, unless otherwise stated. 


\section{Introduction}

Mucopolysaccharidosis type IVA (MPS IVA, OMIM \#253000, Morquio A syndrome) is an autosomal recessive lysosomal storage disease. MPS IVA is characterized by a deficiency of the lysosomal enzyme $\mathrm{N}$-acetylgalactosamine6-sulfatase (GALNS), which is required for the degradation of the glycosaminoglycans (GAGs), keratan sulfate (KS) and chondroitin-6-sulfate (CS) [1]. This enzyme deficiency leads to an abnormal accumulation of KS and CS, and their excretion in the urine [1]. GALNS deficiency distinguishes MPS IVA, the more common form, from mucopolysaccharidosis type IVB in which beta-galactosidase activity is deficient [1].

Progressive accumulation of KS and CS primarily in cartilage and the extracellular matrix results in systemic skeletal dysplasia, which varies in severity but is present in all patients [2]. Clinical features of those with the classical phenotype include short stature, prominent forehead, short neck, pectus carinatum, kyphoscoliosis, genu valgum, hypermobile joints and cervical instability with spinal cord compression [2]. These abnormalities all restrict patient mobility and endurance [2].

Instability of the cervical spine due to odontoid process hypoplasia and ligamentous laxity may lead to dislocation and compression of the cervical cord, resulting in cervical myelopathy and paralysis [3]. The severe skeletal dysplasia also causes chest wall restriction, which can be exacerbated by respiratory muscle weakness associated with cervical myelopathy. Furthermore, laryngeal narrowing and tracheal and bronchial abnormalities cause airway obstruction [3, 4]. These result in dyspnoea, recurrent respiratory infections and sleep-disordered breathing and may progress to respiratory failure [5].

Additional symptoms of MPS IVA may include hearing loss, corneal clouding and heart valvular disease, among others [5]. Life expectancy varies by phenotype. Patients with severe disease may survive only to late childhood or adolescence, whereas patients with more attenuated forms may live to $20-40$ years of age; occasionally, patients survive for more than 60 years $[6,7]$. Death is usually due to respiratory failure or spinal cord compression [6].

MPS IVA is a rare disorder and, although reliable and consistent reports of global incidence are not available, national and regional estimates of birth prevalence range from 1 in 76,000 live births in Northern Ireland to 1 in 641,000 live births in Western Australia [8, 9]. Data for MPS IVA in Asian populations are scarce, but available estimates of birth prevalence include 1 in 500,000 live births in Japan and 1 in 304,000 live births in Taiwan $[10,11]$.

International guidelines recommend multiple approaches for the management of MPS IVA. These include surgery to address musculoskeletal manifestations, vaccination and/or prompt aggressive treatment for respiratory infections, cardiac valve replacement, and vision and hearing aids [12]. Enzyme replacement therapy (ERT) with recombinant elosulfase alfa is an emerging treatment for MPS IVA. In a phase 3 trial, weekly dosing with elosulfase alfa was found to improve endurance, as measured by the 6-min walk test (6-MWT), and reduce urine KS levels [13]. Treatment guidelines recommend initiating ERT as soon as the diagnosis of MPS IVA is confirmed [12].

While information on the natural history of MPS IVA in broad populations is available from large international studies, $[14,15]$ studies in Asian populations are scarce, although some data are available for Taiwan and Korea $[16,17]$. The aim of this study is to document the natural history of MPS IVA and better understand the spectrum of disease in Malaysian patients.

\section{Patients and methods}

The Malaysia Morquio A Programme (MyMAP) is a first multicentre attempt to describe the clinical, biochemical and genetic profiles of all MPS IVA patients in Malaysia. After securing informed consent from patients and/or their parents, all Malaysian patients with MPS IVA were enrolled from the genetics clinics of Hospital Kuala Lumpur, Hospital Pulau Pinang and University Malaya Medical Centre, Kuala Lumpur. Diagnosis of MPS IVA was confirmed by a clinical geneticist based on documented reduced GALNS activity in leukocytes and/or molecular analysis of the GALNS gene. This study was approved by the Medical Research and Ethics Committee, Ministry of Health, Malaysia.

Between November 2014 and November 2016, 21 patients from 16 families were enrolled, representing all the confirmed MPS IVA patients in Malaysia. None of the patients had received haematopoietic stem cell transplant or ERT at the time of recruitment. To calculate birth prevalence, estimates of total live births in Malaysia from the birth year of the youngest patient to that of the oldest (years 1985 to 2013) were obtained from the Department of Statistics Malaysia. Data were collected according to prespecified study procedures and it was anticipated that not all subjects would have completed all assessments. Patients' medical records were retrospectively reviewed for medical history, clinical manifestations, radiology findings, surgical procedures and laboratory studies. Clinical data collected during the study period included height, weight and physical examination, such as general appearance, neurological examination and muscle strength. Muscle strength was graded according to the Medical Research Council's muscle power scale [18]. For the purpose of this study, the patients were classified as severe phenotype if height measurements plotted below the 90th percentile in published growth charts for MPS IVA [19]. Endurance was assessed during the study period with a 6 -MWT performed according to published guidelines [20]. 
The patients were referred to various clinical specialists during the study period and any results from these assessments were recorded from their medical records. Ophthalmological data collected included best corrected visual acuity (measured using the appropriate chart according to age), presence of corneal clouding, glaucoma, pigmentary retinopathy and optic disc changes from slit lamp examination, indirect ophthalmoscopy and cycloplegia refraction. Age-appropriate audiometry data on subjects' hearing ability, standard 2-dimensional Doppler echocardiography data and spirometry parameters such as forced vital capacity (FVC) and forced expiratory volume in $1 \mathrm{~s}$ (FEV1) were recorded. The patients may not have attended all the assessments.

Results of leukocyte GALNS enzyme activity analysis, quantitative urine GAGs analysis, and qualitative urine KS and CS analysis, per local laboratory guidelines, were retrospectively obtained from medical records.

\section{Mutation analysis}

Approximately 5 to $10 \mathrm{~mL}$ of peripheral blood was collected from both patients and their parents for molecular analysis of the GALNS gene at the Institute for Medical Research, Kuala Lumpur. Genomic DNA was extracted using the QIAcube system (Qiagen) and both the quantity and quality of extracted DNA were measured using a NanoDrop ND-1000 Spectrophotometer (NanoDrop). Primers were designed in-house to amplify all 14 coding exons and flanking intronic sequences of the GALNS gene (NM_000512.4). Amplification was performed using touchdown PCR protocol as described by Azize et al. [21]. Purification of PCR products and Sanger sequencing was performed as described by Abdul Wahab et al. [22].

Sequencing results were aligned to the GALNS gene reference sequence (NM_000512.4) using SeqScape software v.3.0 (Applied Biosystems) to identify DNA variants. All variants identified were compared against The Human Gene Mutation Database (HGMD) (http://www.hgmd.cf.ac. uk/ac/index.php) [23], ClinVar (https://www.ncbi.nlm.nih. gov/clinvar/) [24], Genome Aggregation Database (gnomAD) (http://gnomad.broadinstitute.org/) [25] and the GALNS Mutation Database (http://galns.mutdb.org/) [26]. Novel variants were further checked using variant data from both the 100 genomes of Singaporean Malays retrieved from the Singapore Sequencing Malay Project (SSMP) (http://phg.nus.edu.sg/StatGen/public_html/SSMP/ SSMP_index.html) [27] and the 38 genomes of Singaporean Indians retrieved from the Singapore Sequencing Indian Project (SSIP) (http://phg.nus.edu.sg/StatGen/public_html/ SSIP/supp_methods.html\#) [28].

The pathogenicity of novel DNA variants was evaluated by using four in silico programs: MutationTaster2 (http:// www.mutationtaster.org/) [29], FATHMM-XF (http:// fathmm.biocompute.org.uk/fathmm-xf/) [30], Mendelian Clinically Applicable Pathogenicity Score (M-CAP) (http:// bejerano.stanford.edu/mcap/) [31] and Condel (https:// bbglab.irbbarcelona.org/fannsdb/) [32]. All novel mutations identified in this study were submitted to the GALNS Mutation Database. Parental samples were also tested for the presence of the mutations detected in their child.

Homology modelling was performed to examine the potential effects of the novel missense mutations on protein structure. The crystal structure of the human GALNS enzyme was obtained from the Protein Data Bank (https:// www.rcsb.org/; PDB ID:4FDI) [33] and, using this structure as a template, we modelled the protein structures for novel missense mutations using SWISS-MODEL (https:// swissmodel.expasy.org/) [34]. Visual comparison between wild type and mutant protein structures was carried out using PyMOL Molecular Graphics System version 2.1.1 (Schrödinger, LLC).

\section{Statistical analysis}

Descriptive statistics, including means and standard deviations, were calculated. Standard deviation scores (z-scores) for height were calculated using standard growth measures from the World Health Organization (WHO) as comparators $[35,36]$. All statistical analyses were performed using Stata MP v15.1 (College Station, TX, USA).

\section{Results \\ Medical history and demographics}

The clinical manifestations and GALNS mutations identified in the 21 MPS IVA patients (15 females, 6 males; mean age $15.5 \pm 8.1$ years, range 3.4-30.9 years) in this study are shown in Tables 1 and 2. Based on an estimated 14.7 million live births from 1985 to 2013, we estimate the national birth prevalence of MPS IVA in Malaysia to be 1 per 701, 000 live births. Patients were mostly aged younger than 20 years (71\%) and 57\% were Malay, 29\% were Chinese and $14 \%$ were Indian. This distribution of ethnic backgrounds is broadly in line with that of the Malaysian general population, which comprises $68.6 \%$ local ethnic groups of mostly Malays, 23.4\% Chinese and 7\% Indian [37]. All patients were still being followed up at time of writing except for patient 15 , who passed away at the age of 18.5 years due to respiratory failure associated with a lung infection.

The mean ages at first reported symptoms and confirmed diagnosis were $2.6 \pm 2.1$ and $6.9 \pm 4.5$ years, respectively. The most common first symptoms reported by carers were pectus carinatum (57\%), followed by knock knees (43\%; Table 2). Seven patients (33\%), all aged less than 15 years, used no assistive device for walking, while the remainder used a wheelchair and/or a walker (67\%). One patient (5\%) used a bi-level positive pressure (BIPAP) breathing device. 
Table 1 Clinical and molecular characteristics of Malaysian MPS IVA patients

\begin{tabular}{|c|c|c|c|c|c|c|c|c|c|c|c|}
\hline \multirow[t]{2}{*}{$\mathrm{Pt}$} & \multirow[t]{2}{*}{ Sex } & \multirow[t]{2}{*}{ Ethnicity } & \multirow{2}{*}{$\begin{array}{l}\text { Age at first } \\
\text { symptoms, } \\
\text { years }\end{array}$} & \multirow{2}{*}{$\begin{array}{l}\text { Age at } \\
\text { diagnosis, } \\
\text { years }\end{array}$} & \multirow{2}{*}{$\begin{array}{l}\text { Current age, } \\
\text { years }\end{array}$} & \multirow[t]{2}{*}{ Height, cm } & \multirow{2}{*}{$\begin{array}{l}\text { Height } \\
\text { z-score }\end{array}$} & \multirow{2}{*}{$\begin{array}{l}\text { 6-MWT, } \\
\text { metres }\end{array}$} & \multirow{2}{*}{$\begin{array}{l}\text { Assistive } \\
\text { device }\end{array}$} & \multicolumn{2}{|l|}{ GALNS gene mutation } \\
\hline & & & & & & & & & & 1st Allele & 2nd Allele \\
\hline 1 & $\mathrm{~F}$ & Malay & 0.2 & 2 & 3.4 & 91 & -1.81 & NP & None & $c .502 \mathrm{G}>\mathrm{T}$ & c. $503 \mathrm{G}>\mathrm{T}$ \\
\hline 2 & $\mathrm{~F}$ & Malay & 1 & 1.7 & 3.4 & 78.8 & -4.85 & NP & None & c.473_477delAGTGG & c. $1364+1 G>A$ \\
\hline 3 & $\mathrm{~F}$ & Malay & 2 & 4 & 4 & 85.8 & -3.93 & 246.95 & None & c.647T >C & c. $958 \mathrm{G}>\mathrm{A}$ \\
\hline 4 & $\mathrm{~F}$ & Malay & 4 & 6 & 6 & 97 & -3.54 & 300 & None & c. $812 \mathrm{~T}>\mathrm{C}$ & c.950G $>A$ \\
\hline 5 & M & Indian & 2 & 3.9 & 8.8 & 90 & -6.99 & 183 & None & c. $235 \mathrm{~T}>\mathrm{C}$ & c. $235 \mathrm{~T}>\mathrm{C}$ \\
\hline 6 & M & Malay & 2 & 4 & 9.3 & 85.3 & -7.98 & 296 & None & c.1523T >C & C. $812 T>C$ \\
\hline $7^{a}$ & $\mathrm{~F}$ & Chinese & 5 & 6.2 & 10.1 & 97 & -6.58 & 96 & Wheelchair & c.953T>G & c.106_111delCTGCTC \\
\hline 8 & $\mathrm{~F}$ & Malay & 2 & 5 & 12.3 & 88 & -9.44 & 278 & Wheelchair & c. $463 \mathrm{G}>\mathrm{A}$ & mutation not found \\
\hline $9^{b}$ & $\mathrm{~F}$ & Malay & 0.5 & 5.7 & 14 & 95.5 & -9.26 & $N P$ & None & NP & NP \\
\hline 10 & $\mathrm{~F}$ & Chinese & 1 & 2 & 15.5 & 92.5 & -10.20 & 219 & Wheelchair & C.398A $>C$ & c.106_111delCTGCTC \\
\hline $11^{\mathrm{b}}$ & $\mathrm{F}$ & Malay & 1 & 8 & 16 & 97 & -9.65 & NP & Wheelchair & NP & NP \\
\hline $12^{a}$ & $\mathrm{~F}$ & Chinese & 3 & 6 & 16.7 & 89 & -10.98 & 50 & Wheelchair & NP & NP \\
\hline 13 & M & Indian & 3 & 7.8 & 16.8 & 124 & -6.62 & 50 & Walker & c. $218 A>G$ & c. $551 \mathrm{G}>\mathrm{A}$ \\
\hline 14 & $\mathrm{~F}$ & Chinese & 2 & 11 & 17.4 & 93 & -10.51 & 21.5 & $\begin{array}{l}\text { Walker, } \\
\text { Wheelchair }\end{array}$ & c. $346 \mathrm{G}>\mathrm{A}$ & mutation not found \\
\hline $15^{\mathrm{c}}$ & $\mathrm{F}$ & Malay & 1 & 10 & 18.3(died) & 85 & -11.86 & $\begin{array}{l}\text { Cannot } \\
\text { walk }\end{array}$ & Wheelchair & NP & NP \\
\hline $16^{\mathrm{a}}$ & $\mathrm{F}$ & Chinese & 6 & 7.7 & 21.6 & 99.5 & -9.73 & 48 & Wheelchair & c.953T>G & c.106_111delCTGCTC \\
\hline $17^{d}$ & M & Malay & 6 & 12 & 22.5 & 116 & -8.29 & $\begin{array}{l}\text { Cannot } \\
\text { walk }\end{array}$ & Wheelchair & c. $.953 \mathrm{~T}>\mathrm{G}$ & mutation not found \\
\hline 18 & M & Indian & 2 & 18 & 25 & 97 & -10.9 & $\begin{array}{l}\text { Cannot } \\
\text { walk }\end{array}$ & $\begin{array}{l}\text { Wheelchair, } \\
\text { BIPAP }\end{array}$ & c. $647 \mathrm{~T}>\mathrm{C}$ & c. $647 \mathrm{~T}>\mathrm{C}$ \\
\hline $19^{c}$ & M & Malay & 1 & 3 & 26.4 & 87 & -12.3 & $\begin{array}{l}\text { Cannot } \\
\text { walk }\end{array}$ & Wheelchair & c.473_477delAGTGG & c. $1364+1 G>A$ \\
\hline 20 & $\mathrm{~F}$ & Chinese & 2 & 4 & 26.9 & 92.8 & -10.76 & 259.2 & $\begin{array}{l}\text { Walker, } \\
\text { Wheelchair }\end{array}$ & C. $512 A>C$ & c.106_111delCTGCTC \\
\hline $21^{d}$ & $\mathrm{~F}$ & Malay & 8 & 17 & 30.9 & 83 & -12.25 & 50.7 & Wheelchair & c. $.953 \mathrm{~T}>\mathrm{G}$ & mutation not found \\
\hline
\end{tabular}

Current age, denotes age at recruitment

$a, b, c, d$, denotes respective siblings

Abbreviations: 6-MWT 6-min walk test; BIPAP bi-level positive pressure breathing assistance; del Deletion, $F$ Female, $M$ Male, NP Not performed, Pt Patients

Eight patients (38\%) had undergone at least one surgical intervention, occurring before the age of 14 years. Knee surgery, performed in six patients (29\%), was the most common surgical procedure, followed by cervical spine surgery (24\%) (Fig. 1).

\section{Results of physical examinations and MRI spine}

All our patients had the classical physical features described for MPS IVA - pectus carinatum, genu valgum and hypermobile wrist joints - although no formal assessments of joint range of motion were performed. All patients had significant short stature with mean z-scores ranging from -3.5 for those aged 4 years and younger, to -10.7 for those older than 20 years of age (Table 2). All the patients in our study (100\%) had the severe phenotype. Approximately half the patients $(57 \%)$ had documented hyperreflexia and 38\% had clonus, indicating upper motor neuron lesion (Fig. 1). Thirteen patients had muscle power documented. Muscle weakness of MRC grade 3 and below was noted in wrist extension and flexion for six patients (46\%) and in hip flexion for seven patients (54\%). Handgrip weakness was noted in most patients although no formal assessment was performed. Spinal magnetic resonance imaging (MRI) data for 12 patients showed that eight patients (67\%) had cervical stenosis, three patients $(25 \%)$ had thoracic stenosis and five patients (42\%) had atlantoaxial subluxation.

\section{Endurance and respiratory function}

The patients displayed limited endurance and respiratory function. Thirteen patients completed a 6-MWT (Table 1) . Of the eight patients who did not perform the 6-MWT, two were less than 4 years old and did not cooperate, two were post-operative and four - all older than 18 years could no longer walk. Shorter mean walking distances were noted with increasing age (Table 3). Spirometry data 
Table 2 Patient demographic, first symptoms and anthropometric data

\begin{tabular}{|c|c|c|}
\hline Demographic & Number of patients & \\
\hline Total patients & 21 (16 families) & \\
\hline Female & $15(71 \%)$ & \\
\hline Male & $6(29 \%)$ & \\
\hline \multicolumn{3}{|l|}{ Ethnicity } \\
\hline Malay & $12(57 \%)$ & \\
\hline Chinese & $6(29 \%)$ & \\
\hline Indian & $3(14 \%)$ & \\
\hline Age at first symptoms & $2.6 \pm 2.1$ (years, mean $\pm S D$ ) & \\
\hline Age at diagnosis & $6.9 \pm 4.5$ (years, mean $\pm S D)$ & \\
\hline \multicolumn{3}{|l|}{ First symptoms as reported by carers } \\
\hline Pectus carinatum & $12(57 \%)$ & \\
\hline Knock knees & $9(43 \%)$ & \\
\hline Kyphosis & $6(29 \%)$ & \\
\hline Short stature & $6(29 \%)$ & \\
\hline Lax wrists & $2(10 \%)$ & \\
\hline Abnormal gait & $1(5 \%)$ & \\
\hline Falls & $1(5 \%)$ & \\
\hline Current age, at recruitment & $15.5 \pm 8.1$ (years, mean $\pm S D)$ & \\
\hline Current height by age category, years & Mean, cm (min, max) & Z-score mean (min, max) ${ }^{a}$ \\
\hline $0-4(n=3)$ & $85.2(78.8,91)$ & $-3.5(-4.8,-1.8)$ \\
\hline $5-9(n=3)$ & $90.8(85.3,97)$ & $-6.2(-8,-3.5)$ \\
\hline $10-14(n=3)$ & $93.5(88,97)$ & $-8.4(-9.4,-6.6)$ \\
\hline $15-19(n=6)$ & $96.8(85,124)$ & $-10(-11.9,-6.6)$ \\
\hline$\geq 20(n=6)$ & $95.8(83,116)$ & $-10.7(-8.3,-12.3)$ \\
\hline
\end{tabular}

Abbreviations: max Maximum, min Minimum, SD Standard deviation, WHO World Health Organization

${ }^{a}$ WHO growth charts used as reference population

were available for 8 patients; mean FVC was $0.6 \mathrm{~L}$ (SD 0.1) in patients 18 years and younger, and $0.9 \mathrm{~L}$ (SD 0.2) in patients older than 18 years. Four patients underwent overnight pulse oximetry monitoring and all showed significant desaturations during sleep (results not shown) but none underwent a formal sleep study to confirm possible obstructive sleep apnoea.

\section{Cardiology}

Fifteen patients underwent echocardiography. The most frequently observed cardiac abnormality was mitral regurgitation (60\%; Fig. 1), followed by thickened mitral valve (33\%), thickened aortic valve (27\%) and aortic regurgitation (27\%). Mean ejection fraction was 58.5\% (SD 24.9).

\section{Ear and eye examinations}

Of the patients who underwent audiometry assessment, almost all $(10 / 11,91 \%)$ had some form of hearing loss. Middle ear effusion was present in seven out of eight patients assessed (88\%; Fig. 1). Seventeen patients underwent complete ocular assessment by ophthalmologist. Of these, all (100\%) had corneal clouding, but none needed corneal transplantation, three (18\%) had glaucoma and none had pigmentary retinopathy or optic disc changes. Hyperopia was the commonest type of refractive error (67\%) among the 15 patients who underwent cycloplegic refraction. Eleven of the 12 patients (92\%) who underwent visual acuity testing had documented vision of 6/12 or better (Fig. 1).

\section{Urine GAGs and GALNS enzyme analysis}

All our patients had reduced GALNS activity (Fig. 1 and Additional file 1: Table S1). Elevated urine GAGs were detected in $89 \%$ of patients, but only $77 \%$ and $69 \%$ were found to have elevated urine KS and CS, respectively.

\section{GALNS gene mutations}

A total of 30 mutant alleles were identified in 17 patients (88.2\%) from 15 different families and the remaining four alleles were unknown (Table 1). The mutant alleles belonged to 18 distinct genotypes: 13 missense, three nonsense, one small deletion and one splice site mutation (Table 4). Of these, eight were novel mutations (Tyr133Ser, 


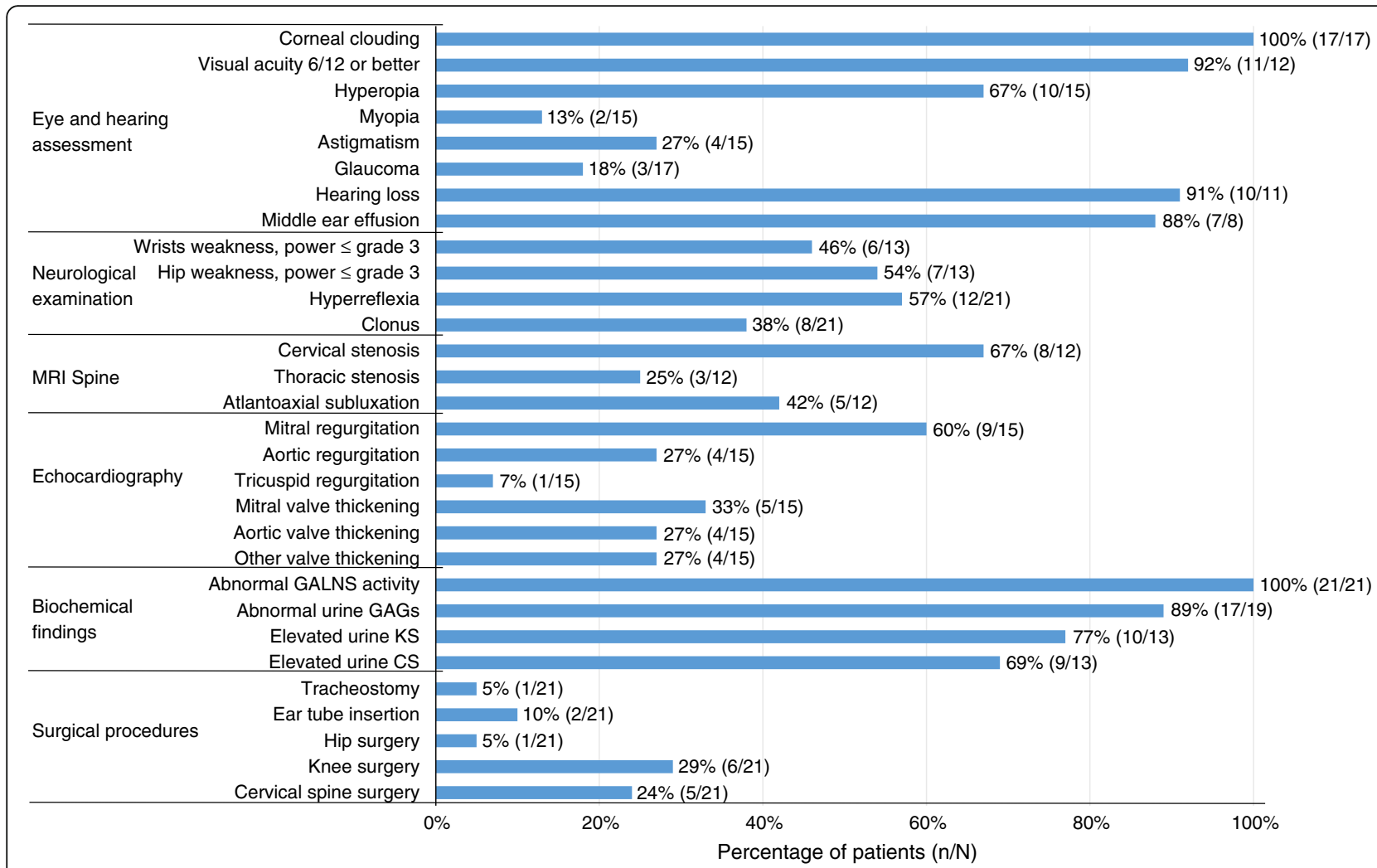

Fig. 1 Frequency of clinical impairments, biochemical abnormalities and surgical procedures in Malaysian MPS IVA patients. Abbreviations: CS, chondroitin6-sulfate; GAG, glycosaminoglycans; GALNS, galactose-6-sulfatase; KS, keratan sulfate; MRI, magnetic resonance imaging

Table 3 6-MWT and FVC in Malaysian MPS IVA patients by age group compared with other studies

\begin{tabular}{|c|c|c|c|}
\hline & \multicolumn{3}{|l|}{ Mean \pm SD } \\
\hline & This study & Harmatz et al. [15] & Lin et al. [16] \\
\hline \multicolumn{4}{|l|}{ 6-MWT } \\
\hline 0-4 years old & $\begin{array}{l}246.9 \mathrm{~m} \\
(n=1)\end{array}$ & $\begin{array}{l}251.6 \pm 121.5 \mathrm{~m} \\
(n=37)\end{array}$ & - \\
\hline $5-11$ years old & $\begin{array}{l}218.8 \pm 98.2 \mathrm{~m} \\
(n=4)\end{array}$ & $\begin{array}{l}232.5 \pm 140.1 \mathrm{~m} \\
(n=127)\end{array}$ & - \\
\hline 12-18 years old & $\begin{array}{l}123.7 \pm 116.4 \mathrm{~m} \\
(n=5)\end{array}$ & $\begin{array}{l}181.2 \pm 177.3 \mathrm{~m} \\
(n=84)\end{array}$ & - \\
\hline$>18$ years old & $\begin{array}{l}119.3 \pm 121.2 \mathrm{~m} \\
(n=3)\end{array}$ & $\begin{array}{l}193.1 \pm 148.5 \mathrm{~m} \\
(n=68)\end{array}$ & - \\
\hline Overall 6-MWT' & $\begin{array}{l}161.4 \pm 110.1 \mathrm{~m} \\
(n=13)\end{array}$ & $\begin{array}{l}212.6 \pm 152.2 \mathrm{~m} \\
(n=316)\end{array}$ & $\begin{array}{l}235.3 \pm 125.5 \mathrm{~m} \\
(n=11)\end{array}$ \\
\hline Overall age & $15.5 \pm 8.1$ years & 14.5 years & $12.6 \pm 6.6$ years \\
\hline \multicolumn{4}{|l|}{ Spirometry, FVC } \\
\hline$\leq 18$ years old & $\begin{array}{l}0.6 \pm 0.1 \mathrm{~L} \\
(n=5)\end{array}$ & $\begin{array}{l}1.1 \pm 0.7 \mathrm{~L} \\
(n=256)\end{array}$ & - \\
\hline$>18$ years old & $\begin{array}{l}0.9 \pm 0.2 \mathrm{~L} \\
(n=3)\end{array}$ & $\begin{array}{l}1.5 \pm 1.1 \mathrm{~L} \\
(n=69)\end{array}$ & - \\
\hline
\end{tabular}

Abbreviations: 6-MWT 6-min walk test, FVC Forced vital capacity, SD Standard deviation

${ }^{a}$ Only patients who completed the test were included
Glu158Valfs*12, Gly168*, Gly168Val, Trp184*, Leu271Pro, Glu320Lys, Leu508Pro). Six recurrent mutations (Leu36 Leu37del, Glu158Valfs*12, Phe216Ser, Leu271Pro, Met 318Arg, c.1364+1G>A) were identified in unrelated patients. Two mutations, Cys79Arg and Phe216Ser, were found homozygous in patients 5 and 18, respectively (Table 1). Patients 5, 15, 18 and 19 had parental consanguinity.

Novel mutations were predicted to be pathogenic by all four in silico programs except for Leu271Pro, which was predicted to be pathogenic by only M-CAP and Condel (Additional file 1: Table S2). Four of the five novel missense mutations (Tyr133Ser, Gly168Val, Leu271Pro, Glu320Lys) affected domain 1 of the human GALNS glycoprotein and the remaining Leu508Pro mutation affected a C-terminal meander region (Fig. 2) [47]. Leu271 is located in an $\alpha$-helix, so substitution to a proline residue would introduce a helix kink that perturbs the overall folding of the protein. Leu508 is located next to Cys507, a residue involved in forming a disulfide bridge with Cys501. Substitution of the small leucine residue to a bulkier proline residue would likely disturb the formation of this important disulfide bridge leading to destabilization of the protein. Since the remaining three mutations are located on the linker/loop region, comparisons of the wild type and mutant protein 
Table 4 Mutations identified in the GALNS gene of 17 Malaysian patients

\begin{tabular}{|c|c|c|c|c|}
\hline Nucleotide change & Amino acid change & Exons/IVS & Allele frequency, $N=34(\%)$ & Reference \\
\hline c.106_111delCTGCTC & p.(Leu36_Leu37del) & 1 & $4(12 \%)$ & $\begin{array}{l}\text { Yang, } 2001 \text { [38]; } \\
\text { Wang } 2010 \text { [39] }\end{array}$ \\
\hline$c .218 \mathrm{~A}>\mathrm{G}$ & p.(Tyr73Cys) & 2 & $1(3 \%)$ & Lee, 2012 [17] \\
\hline c. $235 T>C$ & p.(Cys79Arg) & 2 & $2(6 \%)$ & Bidchol, 2014 [40] \\
\hline c.346G $>A$ & p.(Gly116Ser) & 4 & $1(3 \%)$ & Tomatsu, 2004 [41] \\
\hline c.398A $>C$ & p.(Tyr133Ser) & 4 & $1(3 \%)$ & novel \\
\hline c. $463 \mathrm{G}>\mathrm{A}$ & p.(Gly155Arg) & 5 & $1(3 \%)$ & Bunge, 1997 [42] \\
\hline c.473_477delAGTGG & p.(Glu158Valfs*12) & 5 & $2(6 \%)$ & novel \\
\hline c. $502 \mathrm{G}>\mathrm{T}$ & p.(Gly168*) & 5 & $1(3 \%)$ & novel \\
\hline$c .503 \mathrm{G}>\mathrm{T}$ & p.(Gly168Val) & 5 & $1(3 \%)$ & novel \\
\hline C. $512 \mathrm{~A}>\mathrm{C}$ & p.(Asp171Ala) & 5 & $1(3 \%)$ & Sukegawa, 2000 [43] \\
\hline c. $551 \mathrm{G}>\mathrm{A}$ & p.(Trp184*) & 5 & $1(3 \%)$ & novel \\
\hline c.647T $>C$ & p.(Phe216Ser) & 7 & $3(9 \%)$ & Morrone, 2014 [44] \\
\hline $\mathrm{c} .812 \mathrm{~T}>\mathrm{C}$ & p.(Leu271Pro) & 8 & $2(6 \%)$ & novel \\
\hline c.950G $>A$ & p.(Gly317Glu) & 9 & $1(3 \%)$ & Caciotti, 2015 [45] \\
\hline c.953T>G & p.(Met318Arg) & 9 & $4(12 \%)$ & Ogawa, 1995 [46] \\
\hline c. $958 \mathrm{G}>\mathrm{A}$ & p.(Glu320Lys) & 9 & $1(3 \%)$ & novel \\
\hline c. $1364+1 G>A$ & Skipping of exon 12 & IVS 12 & $2(6 \%)$ & Bunge, 1997 [42] \\
\hline c. $1523 \mathrm{~T}>\mathrm{C}$ & p.(Leu508Pro) & 14 & $1(3 \%)$ & novel \\
\hline
\end{tabular}

Abbreviation: IVS Intervening sequence

structures did not reveal any perceivable impact. However, the substitutions could affect the flexibility and local conformation of the protein.

\section{Discussion}

This study is the first report to describe the clinical, biochemical and genetic profiles of all patients with

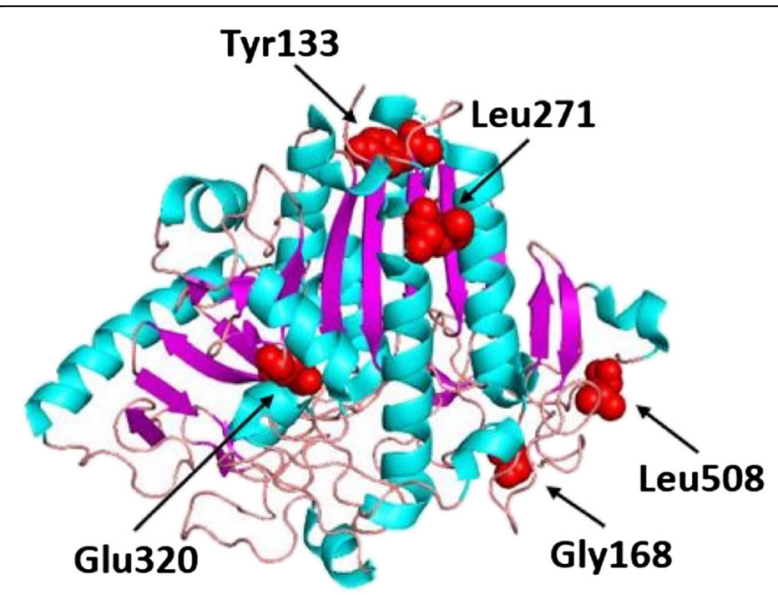

Fig. 2 Location of five novel missense mutations mapped onto the protein structure of the human GALNS protein. Red indicates location of labelled mutations; alpha helices are indicated in cyan, beta sheets in magenta confirmed MPS IVA in Malaysia; it showed that MPS IVA affects all major ethnicities in Malaysia.

The study of MPS IVA patients in Taiwan by Lin and colleagues noted a diverse phenotypic severity, as did the international study by Montaño and colleagues in which $25 \%$ of patients had a mild or intermediate phenotype [14, 16]. All the MPS IVA patients in our study had the severe phenotype. Similarly, Lee and colleagues in Korea reported nine of 10 subjects had the severe phenotype [17]. Our estimated birth prevalence for MPS IVA of 1 per 701,000 live births is lower than those previously reported [8-11]; under-diagnosis of attenuated phenotypes may have contributed to this discrepancy. This highlights the need for increased awareness of MPS IVA, especially of nonclassical symptoms in those with attenuated disease, such as hip stiffness and pain without severe short stature [12] The mean ages at initial symptoms and confirmed diagnosis reported in our study (2.6 and 6.9 years, respectively) are similar to those reported by Montaño et al. (2.1 and 4.7 years), and Lin et al. (2.0 and 5.7 years) $[14,16]$. Common initial presenting symptoms seen in Malaysian patients - pectus carinatum, knock knees and kyphosis are also similar to those observed in Taiwanese MPS IVA patients [16].

The prevalence of surgical interventions in the Malaysian MPS IVA patients was higher than that observed by Lin et al. (33\% any surgical intervention, 13\% undergoing spinal decompression) but similar to that observed in 
the study by Montaño et al. (51\% of patients underwent spinal decompression) $[14,16]$. Harmatz and colleagues reported a surgery prevalence of $71 \%$ in an MPS IVA population with an average age of 14.5 years [15]. The variable prevalence of surgical interventions among MPS IVA patients in these studies may be due to the diverse phenotypic severity but it may also reflect differing surgical practices in each country or region. For example, indication for surgery is less straightforward for prophylactic cervical fusion and/or decompression at an early age highlighting the need for more studies on timing of surgery and long term outcomes [3].

The limitations in endurance seen in our study appear to be more severe than those previously reported by Harmatz et al. [15] and Lin et al. [16] (Table 3). This may be explained by the older mean age and the severe phenotype of our study cohort. Nineteen percent of our patients can no longer walk. Mobility limitations in patients with MPS IVA may be due to atlantoaxial subluxation, progressive spinal compression, reduced respiratory function [14, 15] and progressive debilitating genu valgum [48]. This highlights the importance of monitoring and surgical interventions for the spine and lower limbs.

Our patients also had lower FVC values than those reported by Harmatz et al. [15]. This may be because of the severe phenotype as FVC volumes are affected by reduced height, malformed thorax and reduced upper airway patency [15]. Cardiac abnormalities, in particular mitral regurgitation and thickened mitral valve, were common in our MPS IVA population. Similar findings were reported in Taiwanese MPS IVA patients, where $45 \%$ of patients had mitral regurgitation and $32 \%$ had mitral stenosis [16], and in a study of German MPS IVA patients, where $28 / 54$ (52\%) of patients had valve thickening [49].

Many patients in our study had wrist joint weakness and laxity, a defect that is highly prevalent in MPS IVA patients [50]. The combination of reduced strength and wrist hypermobility greatly limits hand function and curtails many activities of daily living that involve gripping objects. Interventions aimed at maintaining wrist function may be valuable for improving patients' abilities to perform daily activities independently.

All our patients had corneal clouding but none needed corneal transplantation, and most of the patients had visual acuity of $6 / 12$ or better. Mild corneal clouding is typically reported in MPS IVA [51], although severe clouding has also been reported [52].

The mutational spectrum in the GALNS gene is highly heterogeneous among patients with MPS IVA in Malaysia. Nine of 14 coding exons were found to harbour diseasecausing mutations. Despite this heterogeneity, we found that exon 5 was the most commonly mutated region, followed by exons 9 and 1 . Mutations in these three exons accounted for more than half $(51 \%)$ of the mutant alleles identified. These potential hotspot regions could facilitate the design of targeted molecular assays for rapid screening of mutations in the GALNS gene in Malaysian patients with MPS IVA. The second disease-causing mutation could not be identified in $23.5 \%$ of our patients, and this proportion is comparable to previous reports $[44,53]$. This may be due to the presence of mutations, such as large deletions [45] or mutations within deep intronic regions [54], that are not detectable by sequence analysis. Therefore, incorporating other techniques, such as mRNA analysis and copy-number variation (CNV) assays, into the testing workflow for GALNS gene analysis could improve the diagnostic yield.

We found that missense mutation is the most common mutation type in the GALNS gene, and this matches the trend observed in HGMD [23]. One of the 10 most frequently reported mutations in the GALNS gene (Met318Arg) was found to be recurrent in our patients, and this is consistent with the high prevalence of this mutation among patients from the East and Southeast Asian region [55]. The use of variant data from 100 Singaporean Malays and 38 Singaporean Indians will enable identification of population-specific rare variants, and the availability of genetic data from an even larger cohort of this underrepresented population will further enhance our understanding of the genetic basis of this disease [56]. Based on the GALNS mutation reporting guidelines proposed by Morrone and colleagues [44], 14 of $18(77.7 \%)$ distinct mutations in our patient cohort could be considered disease-associated, either because the mutation was identified in multiple unrelated patients or the predicted impact of the mutation on the protein was clear-cut. The remaining four missense mutations (Tyr133Ser, Gly168Val, Glu320Lys, Leu508Pro) were predicted to be pathogenic by all four in silico programs used and were considered likely to be diseaseassociated due to the presence of disease-associated mutations in trans [44]. The novel mutations identified in this study will be useful for assessing the diagnostic status of individuals related to MPS IVA patients and for genetic counselling purposes.

Our study is limited by incomplete data for many subjects, variable assessment of clinical and biochemical parameters, and the retrospective nature of the analysis. The lack of data on quality of life and activities of daily living also limits assessment of phenotypic severity. The number of patients is small, as is typical for a rare disease, and it is possible that attenuated phenotypes have not been diagnosed.

\section{Conclusion}

Our study has added to the understanding of the natural history, phenotype and genotype of MPS IVA by 
evaluating all confirmed patients in Malaysia. All subjects in the study had the severe phenotype with significant clinical impairments. Regular evaluations and management according to the latest guidelines may improve their quality of life. Establishment of a national patient registry could capture data that can further optimize care and improve our understanding of this disease. In the longer term, the creation of a national centre of expertise for the diagnosis and management of MPS IVA patients may help consolidate and concentrate the diverse fields of medical expertise required to treat these patients. Clinical findings, GALNS enzyme activity testing and molecular analysis are essential for precise diagnosis and prognosis of MPS IVA.

\section{Additional file}

Additional file 1: Table S1. Biochemical characteristics of Malaysian MPS IVA patients. Table S2. In silico prediction of novel missense mutations in the GALNS gene. (DOCX $17 \mathrm{~kb}$ )

\section{Acknowledgments}

We thank the Director General of Health Malaysia for permission to publish this paper. We would like to express our gratitude to the study participants and their families. Support for statistical analysis was provided by Dr. Belinda Butcher, AStat of WriteSource Medical Pty Ltd., Australia. Editorial support for this manuscript was provided by Dr. Alister Smith of MIMS (Hong Kong) Ltd.

\section{Authors' contributions}

HYL, HBC, WTK and TMK performed patient and data acquisition. NAAA, YY and MKNMK performed the molecular analysis. HYL and LHN conceptualized the study and analysed the data. Each author performed data interpretation, drafted and revised at least one section of the manuscript. All authors critically reviewed the manuscript and approved its submission.

\section{Funding}

This study was conducted with a research grant from BioMarin Pharmaceutical Inc. However, BioMarin Pharmaceutical Inc. had no role in the study design, data collection, analysis or interpretation, or in writing the manuscript.

\section{Availability of data and materials}

All data generated or analysed during this study are included in this published article (and its supplementary information files).

\section{Ethics approval and consent to participate}

Informed consent to participate in this study was obtained from study participants and their parents. This study was approved by the Medical Research and Ethics Committee, Ministry of Health, Malaysia.

\section{Consent for publication}

Informed consent was obtained from all study participants and/or their parents for the purpose of this publication.

\section{Competing interests}

HYL, LHN, HBC and MKT have received honoraria from BioMarin and Genzyme for work outside of this study. HLC has received honoraria from BioMarin.

\section{Author details}

'Genetics Department, Hospital Kuala Lumpur, Ministry of Health Malaysia, Jalan Pahang, 50586 Kuala Lumpur, Malaysia. ${ }^{2}$ Unit of Molecular Diagnostics \& Protein, Institute for Medical Research, Ministry of Health Malaysia, Kuala Lumpur, Malaysia. ${ }^{3}$ Department of Paediatrics, Faculty of Medicine, University Malaya, Kuala Lumpur, Malaysia. ${ }^{4}$ Paediatric Department, Hospital Kuala Lumpur, Ministry of Health Malaysia, Kuala Lumpur, Malaysia.
${ }^{5}$ Ophthalmology Department, Hospital Selayang, Ministry of Health Malaysia, Selayang, Malaysia.

Received: 16 March 2019 Accepted: 26 May 2019

Published online: 14 June 2019

\section{References}

1. Muenzer J. Overview of the mucopolysaccharidoses. Rheumatology (Oxford). 2011;50(Suppl 5):v4-12.

2. Khan S, Alméciga-Díaz CJ, Sawamoto K, Mackenzie WG, Theroux MC, Pizarro C, et al. Mucopolysaccharidosis IVA and glycosaminoglycans. Mol Genet Metab. 2017;120:78-95.

3. Solanki GA, Martin KW, Theroux MC, Lampe C, White KK, Shediac R, et al. Spinal involvement in mucopolysaccharidosis IVA (Morquio-Brailsford or Morquio a syndrome): presentation, diagnosis and management. J Inherit Metab Dis. 2013;36:339-55

4. Muhlebach MS, Wooten W, Muenzer J. Respiratory manifestations in mucopolysaccharidoses. Paediatr Respir Rev. 2011;12:133-8.

5. Hendriksz CJ, Al-Jawad M, Berger Kl, Hawley SM, Lawrence R, Mc Ardle C, et al. Clinical overview and treatment options for non-skeletal manifestations of mucopolysaccharidosis type IVA. J Inherit Metab Dis. 2013;36:309-22.

6. Genetics Home Reference. Mucopolysaccharidosis type IV. Available at: https:// ghr.nlm.nih.gov/condition/mucopolysaccharidosis-type-iv. Accessed 1 Nov 2018.

7. Lavery C, Hendriksz C. Mortality in patients with Morquio syndrome a. JIMD Rep. 2014;15:59-66.

8. Nelson J. Incidence of the mucopolysaccharidoses in Northern Ireland. Hum Genet. 1997;101:355-8.

9. Nelson J, Crowhurst J, Carey B, Greed L. Incidence of the mucopolysaccharidoses in Western Australia. Am J Med Genet A. 2003;123A:310-3.

10. Leadley RM, Lang S, Misso K, Bekkering T, Ross J, Akiyama T, et al. A systematic review of the prevalence of Morquio a syndrome: challenges for study reporting in rare diseases. Orphanet J Rare Dis. 2014;9:173.

11. Lin H-Y, Lin S-P, Chuang C-K, Niu D-M, Chen M-R, Tsai F-J, et al. Incidence of the mucopolysaccharidoses in Taiwan, 1984-2004. Am J Med Genet A. 2009; 149A:960-4.

12. Hendriksz CJ, Berger Kl, Giugliani R, Harmatz P, Kampmann C, Mackenzie WG, et al. International guidelines for the management and treatment of Morquio a syndrome. Am J Med Genet A. 2015;167:11-25.

13. Hendriksz CJ, Burton B, Fleming TR, Harmatz P, Hughes D, Jones SA, et al. Efficacy and safety of enzyme replacement therapy with BMN 110 (elosulfase alfa) for Morquio a syndrome (mucopolysaccharidosis IVA): a phase 3 randomised placebo-controlled study. J Inherit Metab Dis. 2014;37:979-90.

14. Montaño AM, Tomatsu S, Gottesman GS, Smith M, Orii T. International Morquio a registry: clinical manifestation and natural course of Morquio a disease. J Inherit Metab Dis. 2007;30:165-74

15. Harmatz P, Mengel KE, Giugliani R, Valayannopoulos V, Lin S-P, Parini R, et al. The Morquio a clinical assessment program: baseline results illustrating progressive, multisystemic clinical impairments in Morquio a subjects. Mol Genet Metab. 2013;109:54-61.

16. Lin H-Y, Chuang C-K, Chen M-R, Chiu PC, Ke Y-Y, Niu D-M, et al. Natural history and clinical assessment of Taiwanese patients with mucopolysaccharidosis IVA. Orphanet J Rare Dis. 2014;9:21.

17. Lee NH, Cho SY, Maeng SH, Jeon TY, Sohn YB, Kim SJ, et al. Clinical, radiologic, and genetic features of Korean patients with Mucopolysaccharidosis IVA. Korean J Pediatr. 2012;55:430-7.

18. Medical Research Council. MRC Muscle scale. https://mrc.ukri.org/research/ facilities-and-resources-for-researchers/mrc-scales/mrc-muscle-scale/. Accessed 10 Dec 2018

19. Montaño AM, Tomatsu S, Brusius A, Smith M, Orii T. Growth charts for patients affected with Morquio a disease. Am J Med Genet A. 2008;146A:1286-95.

20. ATS Committee on Proficiency Standards for Clinical Pulmonary Function Laboratories. ATS statement: guidelines for the six-minute walk test. Am J Respir Crit Care Med. 2002;166:111-7.

21. Azize NAA, Ngah WZW, Othman Z, Md Desa N, Chin CB, Md Yunus Z, et al. Mutation analysis of glycine decarboxylase, aminomethyltransferase and glycine cleavage system protein-H genes in 13 unrelated families with glycine encephalopathy. J Hum Genet. 2014;59:593-7.

22. Abdul Wahab SA, Yakob Y, Abdul Azize NA, Md Yunus Z, Huey Yin L, Mohd Khalid MKN, et al. Clinical and mutational analysis of the GCDH gene in Malaysian patients with Glutaric aciduria type 1. Biomed Res Int. 2016;2016: 4074365. 
23. Stenson PD, Mort M, Ball EV, Evans K, Hayden M, Heywood S, et al. The human gene mutation database: towards a comprehensive repository of inherited mutation data for medical research, genetic diagnosis and nextgeneration sequencing studies. Hum Genet. 2017;136:665-77.

24. Landrum MJ, Lee JM, Benson M, Brown GR, Chao C, Chitipiralla S, et al. ClinVar: improving access to variant interpretations and supporting evidence. Nucleic Acids Res. 2018;46:D1062-7.

25. Lek M, Karczewski KJ, Minikel EV, Samocha KE, Banks E, Fennell T, et al. Analysis of protein-coding genetic variation in 60,706 humans. Nature. 2016; 536:285-91.

26. Buck Institute, University of San Francisco. GALNS Mutation Database. http:// galns.mutdb.org/. Accessed 24 Jan 2019.

27. Wong L-P, Ong RT-H, Poh W-T, Liu X, Chen P, Li R, et al. Deep whole-genome sequencing of 100 southeast Asian Malays. Am J Hum Genet. 2013;92:52-66.

28. Wong L-P, Lai JK-H, Saw W-Y, Ong RT-H, Cheng AY, Pillai NE, et al. Insights into the genetic structure and diversity of 38 south Asian Indians from deep whole-genome sequencing. PLoS Genet. 2014;10:e1004377.

29. Schwarz JM, Cooper DN, Schuelke M, Seelow D. MutationTaster2: mutation prediction for the deep-sequencing age. Nat Methods. 2014;11:361-2.

30. Rogers MF, Shihab HA, Mort M, Cooper DN, Gaunt TR, Campbell C. FATHMM-XF: accurate prediction of pathogenic point mutations via extended features. Bioinformatics. 2018;34:511-3.

31. Jagadeesh KA, Wenger AM, Berger MJ, Guturu H, Stenson PD, Cooper DN, et al. M-CAP eliminates a majority of variants of uncertain significance in clinical exomes at high sensitivity. Nat Genet. 2016;48:1581-6.

32. González-Pérez A, López-Bigas N. Improving the assessment of the outcome of nonsynonymous SNVs with a consensus deleteriousness score, Condel. Am J Hum Genet. 2011;88:440-9.

33. Berman HM, Westbrook J, Feng Z, Gilliland G, Bhat TN, Weissig H, et al. The Protein Data Bank. Nucleic Acids Res. 2000;28:235-42.

34. Waterhouse A, Bertoni M, Bienert S, Studer G, Tauriello G, Gumienny R, et al. SWISS-MODEL: homology modelling of protein structures and complexes. Nucleic Acids Res. 2018;46:W296-303.

35. World Health Organization. The WHO Child Growth Standards. http://www. who.int/childgrowth/standards/en/. Accessed 9 Dec 2018.

36. World Health Organization. Growth reference data for 5-19 years. https:// www.who.int/growthref/en/. Accessed 9 Dec 2018.

37. Department of Statistics Malaysia. Current population Estimates, Malaysia, 2014-2016. https://www.dosm.gov.my/v1/index.php?r=column/pdfPrev\&id= OWlxdEVoYIJCSOhUZZJyRUcvZEYxZz09. Accessed 24 Jan 2019.

38. Yang CF, Tsai FJ, Lin SP, Lee CC, Wu JY. A novel in-frame deletion mutation (c106-111del) identified in a Taiwan Chinese patient with type IVA mucopolysaccharidosis. Hum Mutat. 2001;18:254.

39. Wang Z, Zhang W, Wang Y, Meng Y, Su L, Shi H, et al. Mucopolysaccharidosis IVA mutations in Chinese patients: 16 novel mutations. J Hum Genet. 2010;55:534-40.

40. Bidchol AM, Dalal A, Shah H, Suryanarayana S, Nampoothiri S, Kabra M, et al. GALNS mutations in Indian patients with mucopolysaccharidosis IVA. Am J Med Genet A. 2014;164A:2793-801.

41. Tomatsu S, Dieter T, Schwartz IV, Sarmient P, Giugliani R, Barrera LA, et al. Identification of a common mutation in mucopolysaccharidosis IVA: correlation among genotype, phenotype, and keratan sulfate. J Hum Genet. 2004:49:490-4.

42. Bunge S, Kleijer WJ, Tylki-Szymanska A, Steglich C, Beck M, Tomatsu S, et al. Identification of 31 novel mutations in the N-acetylgalactosamine-6sulfatase gene reveals excessive allelic heterogeneity among patients with Morquio a syndrome. Hum Mutat. 1997;10:223-32

43. Sukegawa K, Nakamura H, Kato Z, Tomatsu S, Montaño AM, Fukao T, et al. Biochemical and structural analysis of missense mutations in $\mathrm{N}$ acetylgalactosamine-6-sulfate sulfatase causing mucopolysaccharidosis IVA phenotypes. Hum Mol Genet. 2000;9:1283-90.

44. Morrone A, Tylee KL, Al-Sayed M, Brusius-Facchin AC, Caciotti A, Church HJ, et al. Molecular testing of 163 patients with Morquio a (Mucopolysaccharidosis IVA) identifies 39 novel GALNS mutations. Mol Genet Metab. 2014;112:160-70.

45. Caciotti A, Tonin R, Rigoldi M, Ferri L, Catarzi S, Cavicchi C, et al. Optimizing the molecular diagnosis of GALNS: novel methods to define and characterize Morquio-a syndrome-associated mutations. Hum Mutat. 2015; 36:357-68.
46. Ogawa T, Tomatsu S, Fukuda S, Yamagishi A, Rezvi GM, Sukegawa K, et al. Mucopolysaccharidosis IVA: screening and identification of mutations of the Nacetylgalactosamine-6-sulfate sulfatase gene. Hum Mol Genet. 1995;4:341-9.

47. Rivera-Colón Y, Schutsky EK, Kita AZ, Garman SC. The structure of human GALNS reveals the molecular basis for mucopolysaccharidosis IV a. J Mol Biol. 2012;423:736-51.

48. Cooper GA, Southorn T, Eastwood DM, Bache CE. Lower extremity deformity management in MPS IVA, Morquio-Brailsford syndrome: preliminary report of Hemiepiphysiodesis correction of genu Valgum. J Pediatr Orthop. 2016;36:376-81.

49. Kampmann C, Abu-Tair T, Gökce S, Lampe C, Reinke J, Mengel E, et al. Heart and cardiovascular involvement in patients with Mucopolysaccharidosis type IVA (Morquio-a syndrome). PLoS One. 2016;11:e0162612.

50. Aslam R, van Bommel ACM, Hendriksz CJ, Jester A. Subjective and objective assessment of hand function in Mucopolysaccharidosis IVa patients. JIMD Rep. 2013;9:59-65.

51. Fenzl CR, Teramoto K, Moshirfar M. Ocular manifestations and management recommendations of lysosomal storage disorders I: mucopolysaccharidoses. Clin Ophthalmol. 2015;9:1633-44.

52. Käsmann-Kellner B, Weindler J, Pfau B, Ruprecht KW. Ocular changes in mucopolysaccharidosis IV a (Morquio a syndrome) and long-term results of perforating keratoplasty. Ophthalmologica. 1999;213:200-5.

53. Tomatsu S, Montaño AM, Nishioka T, Gutierrez MA, Peña OM, Tranda Firescu GG, et al. Mutation and polymorphism spectrum of the GALNS gene in mucopolysaccharidosis IVA (Morquio a). Hum Mutat. 2005;26:500-12.

54. Caciotti A, Tonin R, Mort M, Cooper DN, Gasperini S, Rigoldi M, et al. Missplicing of the GALNS gene resulting from deep intronic mutations as a cause of Morquio a disease. BMC Med Genet. 2018;19:183.

55. Morrone A, Caciotti A, Atwood R, Davidson K, Du C, Francis-Lyon P, et al. Morquio a syndrome-associated mutations: a review of alterations in the GALNS gene and a new locus-specific database. Hum Mutat. 2014;35:1271-9.

56. Wu D, Dou J, Chai X, Bellis C, Wilm A, Shih CC, et al. Large-scale wholegenome sequencing of three diverse Asian populations in Singapore. bioRxiv. 2018;390070. Preprint at https://www.biorxiv.org/content/10.1101/390070v1

\section{Publisher's Note}

Springer Nature remains neutral with regard to jurisdictional claims in published maps and institutional affiliations.
Ready to submit your research? Choose BMC and benefit from:

- fast, convenient online submission

- thorough peer review by experienced researchers in your field

- rapid publication on acceptance

- support for research data, including large and complex data types

- gold Open Access which fosters wider collaboration and increased citations

- maximum visibility for your research: over $100 \mathrm{M}$ website views per year

At BMC, research is always in progress.

Learn more biomedcentral.com/submissions 